\title{
Aortic Coarctation
}

\author{
Umberto G. Rossi, MD, EBIR ${ }^{1,2}$ Anna Maria lerardi, MD² Gianpaolo Carrafiello, MD, Prof ${ }^{3}$
}

Maurizio Cariati, MD20

1 Department of Diagnostic Imaging, Interventional Radiology Unit, Ente Ospedaliero Galliera Hospital, Genova, Italy

${ }^{2}$ Department of Diagnostic and Therapeutic Advanced Technology, Diagnostic and Interventional Radiology Unit, Azienda Socio

Sanitaria Territoriale Santi Paolo and Carlo Hospital, Milano, Italy

${ }^{3}$ Department of Services and Preventive Medicine, Radiology Unit, Ca' Granda Fondation, Maggiore Policlinic Hospital, University of Milan, Milano, Italy

\author{
Address for correspondence Umberto G. Rossi, MD, EBIR, \\ Department of Diagnostic Imaging, Interventional Radiology Unit, \\ Ente Ospedaliero Galliera Hospital, Mura delle Cappuccine, \\ 14-16128 Genova, Italy \\ (e-mail: urossi76@hotmail.com).
}

AORTA 2020;8:46-47.
Abstract
Keywords
- aorta
- coarctation
- vascular pathology
- computed tomography
- imaging
- aging

We report a case of a 45-year-old male suffering from arterial hypertension who was found to have an aortic coarctation with marked hypertrophic compensatory collateral arterial circulation. Although coarctation is relatively rare, this must be included in the differential diagnosis in patients with arterial hypertension with a positive gradient between upper and lower limbs.
A 45-year-old male was evaluated for arterial hypertension. A pressure gradient $(18 \mathrm{~mm} \mathrm{Hg}$ ) between upper and lower limbs was noted. Among the various diagnostic examinations, the patient underwent multidetector computed tomography (MD-CT) angiography. This showed an aortic coarctation at the level of isthmus proximal third of thoracic aorta with significant hypertrophic compensatory collateral arterial circulation (-Fig. 1). At the time of diagnosis, endovascular or open surgery treatment were offered to the patient, but he refused all intervention. Therefore, the patient was started on life-long antihypertensive medical treatment with clinical and imaging follow-up.

Aortic coarctation in adults is generally recognized via systemic arterial hypertension associated with a pressure gradient between the upper and lower extremities. ${ }^{1}$ Precise vascular imaging (MD-CT or magnetic resonance imaging) is mandatory for a complete evaluation of the thoracic aorta, its branches, and possible collateral vessels. ${ }^{2,3}$ Criteria for invasive treatment in adult patients include translesional pressure gradient ( $>20 \mathrm{~mm} \mathrm{Hg}$ ) and/or evidence of significant collateral vessels. ${ }^{1,4-6}$ Choice between open surgery versus percutaneous endovascular treatment should be determined by a multidisciplinary team specialists (surgeons, interventional radiologists, and cardiologists). ${ }^{1,7} \mathrm{Fi}-$ nally, all patients affected by aortic coarctation require a life-long treatment of arterial pressure and close follow-up (clinical and imaging). received

September 14, 2018

accepted after revision

December 18, 2019
DOI https://doi.org/

$10.1055 / \mathrm{s}-0040-1701522$.

ISSN $2325-4637$.
Copyright $\odot 2020$ by Thieme Medical Publishers, Inc., 333 Seventh Avenue, New York, NY 10001, USA. Tel: +1(212) 760-0888.
License terms

(1) (1) 


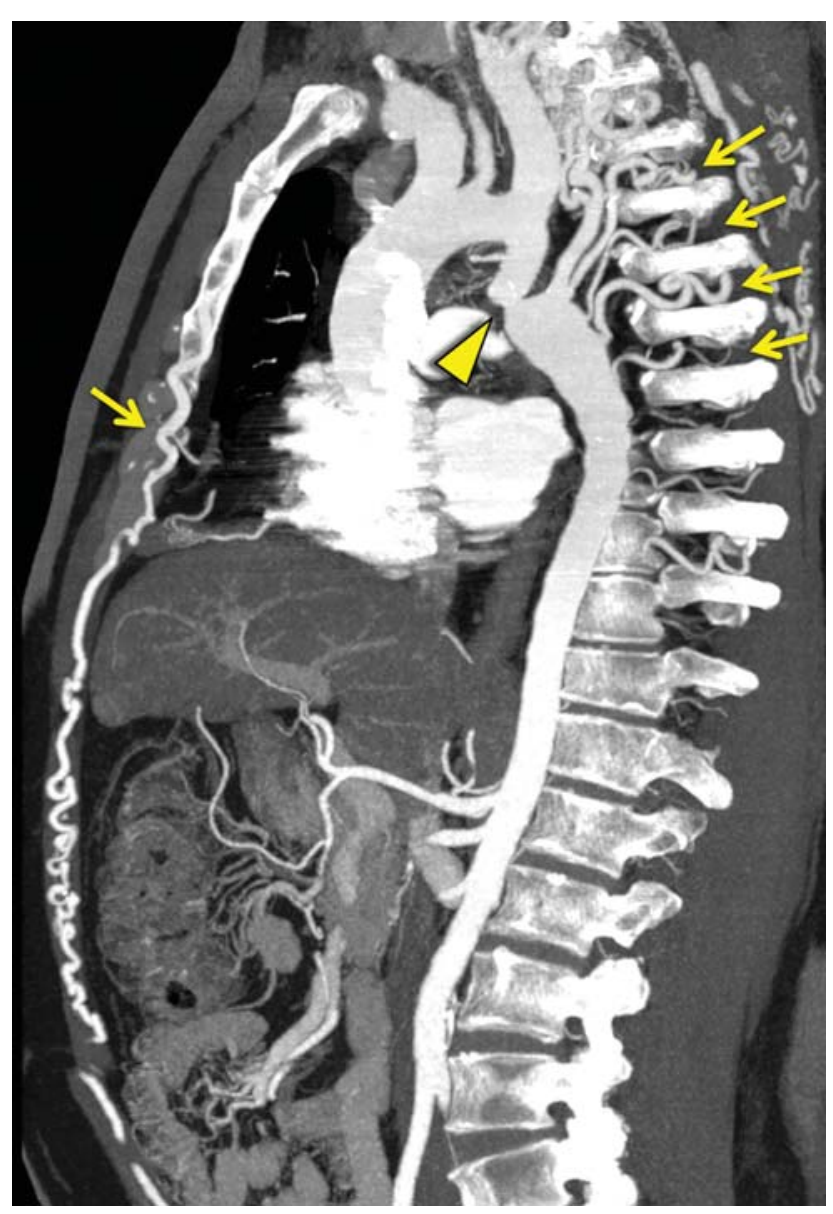

Fig. 1 Multidetector computed tomography angiography sagittal reconstruction demonstrating the presence of aortic coarctation at the level of isthmus proximal third of thoracic aorta (arrowhead) with hypertrophic compensatory collateral arterial circulation from the intercostal and mammary arteries (arrows).

\section{Funding}

This research was funded solely through institutional sources.

\section{Conflict of Interest}

The authors do not report any conflict of interest related to this article.

\section{Acknowledgment}

None.

\section{References}

1 Warnes CA, Williams RG, Bashore TM, et al. ACC/AHA 2008 guidelines for the management of adults with congenital heart disease: a report of the American College of Cardiology/American Heart Association Task Force on Practice Guidelines (writing committee to develop guidelines on the management of adults with congenital heart disease). Circulation 2008;118(23):e714-e833

2 Ferro C, Rossi UG, Seitun S, Scarano F, Passerone G, Williams DM. Aortic branch artery pseudoaneurysms associated with intramural hematoma: when and how to do endovascular embolization. Cardiovasc Intervent Radiol 2013;36(02):422-432

3 Rossi UG, Seitun S, Cariati M. Aortic dissection: the flood tide sign. J Cardiovasc Comput Tomogr 2013;7(05):330-332

4 Ruys TP, Bekkers JA, Duvekot JJ, Roos-Hesselink JW. A pregnant patient with native aortic coarctation and aneurysm. Aorta (Stamford) 2014;2(03):110-112

5 Inaraja Pérez GC, Spitzer Cano E, Angulo Hervías E, López Ramón M, Salazar González JJ, Merchante García P. Images in vascular medicine. Asymptomatic aortic coarctation diagnosed because of a vast calcified collateral circulation. Vasc Med 2014;19(01):75-76

6 Beckmann E, Jassar AS. Coarctation repair-redo challenges in the adults: what to do? J Vis Surg 2018;4:76-88

7 Rossi UG, Santuari D, Dallatana R, Cariati M. Use of iliac branch device for endovascular treatment for abdominal aorta aneurysm with small diameter neck. Aorta (Stamford) 2017;5(06):181-183 